\title{
Mudanças Técnicas e Institucionais e Crescimento Econômico: aproximação teórica a partir das abordagens evolucionária e institucionalista.
}

\author{
Silvio A. F. Cario* \\ William Borges**
}

Resumo: No intuito de construir um quadro analítico que aproxime as teorias NeoSchumpeteriana e Institucionalista, o trabalho procura angariar elementos que tenham o mesmo aporte epistemológico e, ainda, contribuam com o desenvolvimento futuro de novas interpretações no campo. Nesses termos, entende-se que as mudanças ocorrem de forma simultânea e não rotineira, fazendo com que as mudanças repercutam pela cadeia produtiva. Para cumprir com o objetivo, essa pesquisa se configura como teórica, de natureza qualitativa e descritiva. Como resultado, a pesquisa conta com uma aproximação de sete pressupostos que evidenciam uma forma de interpretar os ambientes repletos de ações institucionais e tecnológicas.

\section{Palavras-chave: Inovação. Instituições. Abordagem Complementar.}

In order to construct na analytical framework that approximates the Neo-Schumpeterian and Institutionalist theories, the work seeks to gather elements that have the same epistemological contribution and, also, contribute to the future development of new interpretations in the field. In these terms, it is understood that the changes occur simultaneously and not routinely, causing the changes to pass through the productive chain. In order to fulfill the objetctive, this research is configured as theorical, of a qualitative and descriptive nature. As a result, the reserarch has an approximation of seven assumptions that show a way, of interpreting environments full of institutional and theorical actions.

Key-words: Innovation. Institution. Complementary approach

JEL: 150 - Desenvolvimento econômico, evolução tecnológica e crescimento

ÁREA 5 - Inovação e mudanças técnicas e organizacional e institucional

5.4 Mudança técnica, organizações e instituições

\footnotetext{
* Professor do Departamento de Economia e Relações Internacionais da Universidade Federal de Santa Catarina. E-mail: fecario@yahoo.com.br ** Professor do Instituto Federal de Santa Catarina. E-mail: williamborges_88@ @otmail.com
} 


\section{Mudanças Técnicas e Institucionais: aproximação teórica a partir da integração das abordagens evolucionária e institucionalista.}

\section{INTRODUÇÃO}

O estudo das interações entre os elementos institucionais e tecnológicos demonstra ser um campo de pesquisa complexo, mas com ampla possibilidade de desenvolvimento científico. Tomando-se como referência os delineamentos teóricos da abordagem neo-schumpeteriana e institucionalista, a presente pesquisa se volta para a construção de um quadro analítico que aproxime as duas teorias com o propósito de angariar elementos que tenham o mesmo aporte epistemológico e, ainda, contribuam com o desenvolvimento futuro de novas interpretações no campo.

Mantendo a concepção de que a ciência avança mediante a descoberta de novas formas de se pensar e resolver problemas, os autores que atribuem a sua esfera cognitiva aos NeoSchumpeterianos avançaram no desenvolvimento do termo inovação encarando-o como algo endógeno à dinâmica econômica. A nova roupagem desse pensamento incluiu ao emaranhado teórico de inovações o caráter dinâmico e propulsor que as inovações propiciam para os ambientes organizacionais. Acredita-se que os Neo-Schumpeterianos consideram a tecnologia como algo inerente ao tramite produtivo. Assim, intermediando as relações assimétricas do capitalismo, essa abordagem compactua com a existência desses desníveis entre as organizações e se baseiam neles para criarem pontos estratégicos credíveis à competição.

De forma concomitante, o conceito de instituições vem se transformando ao longo dos anos. A constante preocupação com o escopo de análise das instituições, bem como a sua mensuração tem acolhido a atenção de muitos teóricos da academia em todo o mundo. O seu caráter volátil e maleável denota uma significativa dimensão histórica que deve ser abordada e lapidada com o auxílio das nuances teóricas e contextuais do tempo. Nesse sentido, o ambiente socioeconômico influencia diretamente a concepção estrutural que a temática engendra no tratado das normas, valores, crenças, cultura, entre outras instituições.

Em geral, as concepções que consideram as instituições como uma unidade de análise partem da discussão de suas diferenças com o neoclassicismo e suas afinidades com o evolucionismo, buscando identificar analiticamente pontos de concordância que permitam a constituição de uma possível teoria institucionalista. Isso porque, para os institucionalistas a história importa. As formas de crescimento capitalistas são múltiplas e desuniformes, o que gera uma falha na análise dos neoclássicos do ponto de vista da teoria institucionalista. A abordagem metodológica dos neoclássicos trata os indivíduos de forma independente, com suas preferências dadas, enquanto que na realidade, conforme defende Conceição (2000), os indivíduos são cultural e mutuamente interdependentes.

Essa complementaridade das teorias Neo-Schumpeteriana e Institucional possibilita uma avaliação simultânea entre a "técnica e a criatividade" na solução de problemas. A complementaridade ocorre em um processo retroalimentador, em idas e vindas de influências. Nesse sentido, esse exercício de se observar os dois lados da mesma moeda pode contribuir com a análise e interpretação do meio à luz das influências exercidas pelas ações institucionais de determinado segmento.

A presente pesquisa pode ser delineada como um ensaio teórico, marcadamente de cunho descritivo e interpretativo. O estudo caracteriza-se por ser de natureza qualitativa, haja vista que, no entendimento de vários autores, como Minayo (2010), as pesquisas qualitativas são consistentes em situações que envolvem estudos teóricos. O tratamento teórico analítico 
oferece uma retomada atualizada das ramificações teóricas e, ainda, fortalece o caráter interdependente que está presente nas entrelinhas dos estudos.

Para a melhor compreensão, esse trabalho foi estruturado da seguinte forma a partir desta introdução: o capítulo dois apresenta o tratamento teórico analítico que, por sua vez, está dividido em duas partes, a primeira delas traz as contribuições dos Neo-Schumpeterianos e a segunda avança na delimitação das corretes teóricas que desenvolveram a temática das instituições. O capítulo três contém uma aproximação teórica entre as duas temáticas e apresenta uma proposta de consolidação para futuras análises científicas. Por fim, no capítulo quatro, são apresentadas as considerações finais do estudo.

\section{TRATAMENTO TEÓRICO ANALÍTICO}

\subsection{NEO-SCHUMPETERIANOS: ABORDAGEM HODIERNA SOBRE INOVAÇÃO}

Em meio a mudanças de cunho paradigmático, os teóricos sinalizam uma nova frente teórica, capaz de avançar nas evoluções técnicas, sociais e econômicas. Isso faz com que essa nova abordagem, que se aproxima de uma evolução, condicione o resultado das empresas à sua sobrevivência, de forma que a sua expertise, bem como a sua capacidade dinâmica em atuar num ambiente competitivo gere traços evolutivos ligados diretamente com a sua capacidade de se adaptar às novas realidades organizacionais e ambientais (PEREZ (1992). .

A ideologia por traz das evoluções acarretam o tratamento de uma nova performance organizacional que é a trajetória da dinâmica industrial. Dosi (1988) acredita que essa performance industrial emerge endogenamente, o que de fato, expõe os padrões existentes de mudanças da organização e que podem induzir novos rumos para a trajetória tecnológica em determinado paradigma. Dessa forma, o paradigma tecnológico pode ser definido como proposto por Tavares, Kretzer e Medeiros (2005) como sendo um conjunto de procedimentos que servem de base para nortear pesquisas tecnológicas, onde poderão ser identificados os problemas, além de serem especificados os objetivos que podem ser perseguidos.

Nesse sentido, o paradigma tecno-econômico é importante para incorporar a dimensão organizacional das empresas e do trabalho. Assim, a noção de paradigma já não é só técnica, mas também econômica e institucional, já que a inovação observada no mercado também não é só tecnológica. Com isso, essa poderosa influência sobre todo o sistema deriva da combinação de vantagens técnicas com econômicas, justificando a expressão paradigma técno-econômico (FREEMAN; PEREZ, 1988).

Dessa forma, a trajetória tecnológica, por assim dizer, foi definida por Nelson e Winter (2006) como um padrão de progresso através da solução incremental dos trade-offs explicitados por um paradigma tecnológico. Os autores acreditam que após entrarem em uma determinada trajetória tecnológica a organização gera um impulso próprio para direcionar as suas atividades a fim de buscar soluções aos problemas rotineiros. Sendo que esses problemas são resolvidos mediante o desenvolvimento e sedimentação do progresso técnico (AREND, 2009).

O passado, por assim dizer, importa para o reconhecimento e tratamento das rotinas. Segundo Tigre (2006), as rotinas formam o fator determinante do comportamento das empresas, visto que quando consolidadas elas apresentam a necessidade de coordenação hierárquica, permitindo que as melhores decisões sejam tomadas por indivíduos que conhecem de forma satisfatória o seu trabalho (ORSENIGO, 1995). Dentre as características dessas rotinas, Nelson e Winter (2006) destacam algumas: (1) rotina como memória da organização, isto é, a rotinização das atividades gera um agrupamento de conhecimentos específicos; (2) a rotina como trégua, que é a combinação do mecanismo de imposição de regras e de outras motivações que proporciona satisfação ao quadro de colaboradores em cumprir suas funções dentro da própria rotina organizacional; (3) a rotina como meta: controle, cópia e imitação, em que as 
empresas são postas a definir novas rotinas e para isso utilizam-se da imitação de rotinas de outras empresas; (4) as rotinas atreladas às habilidades, isto é, a compreensão das habilidades individuais informa a compreensão do comportamento da organização; (5) a rotina ótima e rotinas de otimização, de forma que o conhecimento das rotinas é o ponto chave da compreensão do comportamento da organização como um todo; (6) as rotinas, heurísticas e inovação que acarretam em mudanças nas rotinas; (7) rotinas como genes - as informações mais importantes de coordenação são mantidas no funcionamento rotineiro da organização.

Nesse sentido, a inovação não é fruto de um cálculo de otimização, mas sim do recurso a uma heurística, expressa por regras e procedimentos. Além disso, a heurística que caracteriza o processo de busca é fundamentada em conhecimentos humanos limitados e acumulados ao longo do tempo, aos quais, embora não estejam voltados à obtenção de soluções ótimas, permitem gerar inovações (LAPLANE, 1997).

A partir dessas constatações, o aprendizado é encarado como parte constituinte do comportamento das empresas, podendo ser denominado uma espécie de rotina. Malerba (1992) resgata seis tipos de aprendizado condizentes com o processo preparatório que são learning by doing, learning by using, learning by interacting, learning from advances in science and technology, learning from inter-industry, e learning by searching. Todas essas formas de aprendizado constituem uma rotina destinada a preparar as empresas para o futuro. Nonaka e Takeuchi (1997) dizem que a compreensão do conhecimento nos meios inovativo é de fundamental importância, pois o conhecimento explícito pode ser generalizado pela dedução lógica e adquirido por estudos formais.

Entende-se que a chave para a criação de conhecimento organizacional está na capacidade de converter conhecimentos individuais em coletivos. No entanto, também é sabido que para as informações divagarem de forma dinâmica na rede, as instituições devem estar atuando prontamente e a favor dessa nova disseminação de conhecimentos. Nesse sentido, as instituições importam, não pelo fato de existirem, mas pelas conexões que são capazes de criar no ambiente institucional, ou seja, os seus elos no sistema modelam relações e condicionam o preparo para as novas dinâmicas tecnológicas (FREEMAN, 1995).

\subsection{QUADRO EVOLUTIVO DO TRATAMENTO TEÓRICO INSTITUCIONALISTA}

\subsubsection{O Velho Institucionalismo}

Para Veblen (1973) a evolução humana passou por etapas de desenvolvimento que culminaram em sociedades repletas de instituições. Nesse momento, instituições diziam respeito aos hábitos de pensamento que dominavam a ação humana. Como em seu contexto existiam muitas indústrias, cabe salientar que em sua visão, as instituições industriais são aquelas orientadas para a eficiência da produção e para a melhoria do bem-estar material. No entanto, a lógica predominante na obra de Veblen está constantemente em conflito com o caráter instrumental que uma instituição "pode" adotar, mas que não é o único valor preconizado.

Isso porque o autor acreditava que a ciência deveria ser lapidada em prol da sociedade, oferecendo meios e estímulos para o conforto das pessoas. Nesse sentido, o lucro unilateral dos sistemas mercantilistas não coincide com os instrumentos beneficentes da sociedade. Com isso, ele combate ferozmente a ideia liberal de que a orientação pecuniária dos comerciantes conduziria a um ótimo social. Monastério (1998) salienta que a abordagem vebleniana, assume que as exigências materiais de uma sociedade formam os hábitos de vida (habits of life), ou seja, maneiras rotineiras que os indivíduos interagem com o seu habitat.

Percebe-se já na obra de Mitchell (1984) uma tendência, ainda que particular, em trabalhar a esfera institucional na descrição qualitativa dos ciclos econômicos. Em sua obra, o constante balizamento dos ciclos econômicos parece estar atrelado aos relacionamentos das 
cadeias produtivas que, ao iniciar uma mudança, os primeiros a sentirem essa modificação são aqueles que estão próximos do fato, porém, na medida em que o tempo passa e as organizações atuam, as demais organizações também começam a sofrer as consequências. De tal forma que, o que muda de fato, é a intensidade dessa percepção.

Nesse interim, a preocupação com o significado e dimensão das instituições ainda estava presente no pensamento de alguns economistas. Commons (1931, p. 648), em seu tempo, relata em seu primeiro parágrafo o quão difícil é encontrar uma definição adequada ao termo: "The difficulty in defining a field for the so-called institutional economics is the uncertainty of meaning of an institution". Defende também que "[...] sometimes an institution seems to mean a framework of laws or natural rights within which individuals act like inmates. Sometimes it seems to mean the behavior of the inmates themselves".

Existiu, no entanto, um gap entre o tratamento teórico do velho institucionalismo (Veblen, Mitchell e Commons) e os Neo-Institucionalistas que pode ser, em parte, caracterizado pelo avanço que os métodos econométricos tiveram a partir da Segunda Guerra Mundial. O grande problema é que esse novo método não é compatível com a crítica de Veblen ao neoclassicismo. Conforme salientado anteriormente, a Nova Economia Institucional (NEI) retomou a discussão acerca das instituições, mas não pressupunha a falência da teoria neoclássica, ou seja, para os autores da NEI, era possível inserir as instituições nas análises econômicas sem considerar os preceitos do velho institucionalismo.

\subsubsection{A Nova Economia Institucional}

Assim, em meio aos movimentos da Nova Economia Institucional, North (1991) delimita um campo seleto para as instituições, mas que parece ser um início para se desenvolver uma nova roupagem acadêmica. Nesse trabalho precursor, as instituições são definidas como as restrições humanamente construídas onde interagem as estruturas política, econômica e social. As regras formais são compostas por leis, constituição e direitos de propriedade, por outro lado, as sanções, tradições e códigos de conduta são classificados como restrições informais.

Os regramentos formais e informais são responsáveis, segundo Farina (2000), por condicionar o jogo social. Dessa forma, os agentes de mercado iriam realizar o intercâmbio dos direitos de propriedade seguindo regras (formais e informais) criadas por eles mesmos. A evolução das instituições, tema central do trabalho de North (1991), a partir de uma posição econômica, é obtida ao considerar o sequenciamento dos fatos, ou seja, aquilo que já se passou em determinada economia irá influenciar nas determinações futuras. À medida que uma estrutura evolui, ela estabelece um norte para o futuro, seja ele positivo ou negativo. $\mathrm{O}$ desempenho econômico, nessa perspectiva, pode estar relacionado a mudanças institucionais.

Ao considerar as mudanças institucionais e suas influências, é possível identificar outro propósito das instituições, que é controlar os custos de transação entre os agentes econômicos, haja vista a constante manipulação dos regramentos realizada pelos agentes à medida que realizam trocas dos direitos de propriedade. $\mathrm{O}$ contraste que pode ser observado no argumento de North (1993) é fruto da diferença entre dois possíveis conceitos, diferenciando instituições e organizações. A mesma dicotomia é evidente na definição de Commons (1931, p. 648) ao propor que as instituições devem ser compreendidas "as collective action in control, liberation and expansion of individual action". Nessa perspectiva a ação coletiva envolve todas as formas de controle social como família, associações, sindicato, o Estado, entre outras formas. O princípio comum a todas as formas de organização é a presença de maior ou menor grau de controle.

Ao aceitar a complexidade e relevância das instituições para responder aos novos questionamentos envoltos à temática da Nova Economia Institucional, Williamson (2000) 
propõe em seu artigo a subdivisão das instituições da economia em quatro níveis para compreendê-las. No primeiro, chamado de Embeddedness, estão as instituições informais tais como as tradições, normas religiosas, entre outras instituições cuja característica é mudar lentamente e poder surgir de forma espontânea. O Segundo nível é composto pelo ambiente institucional onde estão as regras formais do jogo tais como burocracia, política, jurisdições, entre outros elementos. Descendo mais um nível, estão as instituições de Governança, trata-se de um nível composto pela Economia dos Custos de Transação, e dessa forma, preza que a estrutura de governança esteja alinhada às características da transação. E finalmente, no nível quatro, está a alocação dos recursos que é feita continuamente a depender dos movimentos do mercado. Os quatro níveis propostos por Williamson seguem uma hierarquia rígida, ou seja, o nível inferior responde diretamente ao nível superior.

Conforme observado por Williamson (2000), os autores Arrow. Hayek, Myrdal, Simon, Coase e North são considerados figuras-chave para a evolução da NEI. Coase trouxe um novo entendimento ao explicar a gênese da firma, para ele a firma não seria apenas um espaço de transformação do produto, mas também um campo de coordenação dos agentes através de suas ações (FARINA et al.,1997). Outro autor que ganha destaque na discussão é Simon, que em seu artigo de 1957 intitulado "Models of man" propõe a racionalidade limitada (WILLIAMSON, 1985; ZYLBERSZTAJN, 1995). Embora os custos de transação definidos por Coase tenham sido de fundamental importância para uma nova concepção da firma, o seu insight não permitia testes empíricos devido à falta de base de comparação de tais custos. Assim, para uma efetiva consolidação da NEI, era preciso haver contribuições que permitissem a refutação da proposição de Coase. Os primeiros passos foram dados por Williamson (1975) e Klein et al., (1978).

Quanto ao progresso da NEI, Williamson (2000, p. 596) destaca que a teoria "[...] has progressed not by advancing an overarching theory but by uncovering and explicating the microanalytic features to which Arrow refers and by piling block upon block until the cumulative value added cannot be denied". O termo evolução é empregado de forma proposital na oração para estabelecer um sentido à teoria. Não significa dar novas respostas para as questões tradicionais, mas sim responder aos novos questionamentos que surgiam como, por exemplo, explicar em um segundo momento o porquê das decisões, ou seja, explicar porque as decisões são tomadas de determinada forma e não de outra.

\subsubsection{Abordagem Neo-Institucionalista}

Quando questionado acerca do significado das instituições, Hodgson (2006) é contundente em afirmar que são tipos de estruturas que mais importam na vida social, justamente por compor substancialmente o material da vida social. Nesse sentido, o reconhecimento do relevante papel das instituições na vida comum, envolve o reconhecimento e análise de uma grande variedade de interações e atividades humanas, que vez ou outra estão estruturadas em termos de regras explícitas e implícitas. Nesses termos, a linguagem, o dinheiro, direitos, sistemas de pesos, medidas, modos à mesa, empresas são, portanto, todas instituições.

Para o autor, o que falta a grande parte da literatura é uma explicação dos processos causais envolvidos, perfazendo as influências de cima para baixo que ocorre na interação instituição/indivíduo. Hodgson acredita que a explicação mais satisfatória dos processos relevantes dentre os escritos dos velhos institucionalistas estava em Veblen (1899, p. 190), "A situação de hoje molda as instituições de amanhã através de um processo seletivo e coercitivo, através da ação sobre a visão habitual do homem em relação às coisas".

Ao avaliar o papel das instituições no contexto do desenvolvimento econômico, Pessali e Dalto (2010) sinalizam a existência de uma correlação e causalidade simultâneas que se 
formam nos processos de desenvolvimento. Trata-se de um processo cumulativo e circular, onde as interações ocorrem e, com elas, forma-se uma verdadeira espiral de mudanças que se voltam para a ampliação do bem-estar e da liberdade dos indivíduos. No entanto, essas mudanças dependem do funcionamento das instituições existentes, da sua distribuição de ônus e benefícios transacionais entre os participantes.

Ao interpretar Veblen, Monastério (1998) e Dewey (1950) defendem que os hábitos não se mostram apenas nas atividades, mas também condicionam a reflexão dos indivíduos, formando uma espécie de hábitos de pensamento. Dewey aprofunda a discussão e sinaliza que ocorre uma interpenetração dos hábitos, o que dá unidade à conduta humana. A comuna vivenciada pelos hábitos se influencia mutuamente, perfazendo o indivíduo como um agrupamento complexo de hábitos que compactuam de um mesmo espaço e delimitam a sua existência mediante sua justaposição.

As instituições canalizam e restringem o comportamento de maneira que indivíduos formam novos hábitos. No plano do agente humano, não há forças sociais misteriosas controlando os indivíduos, além das que afetam a ação e a comunicação dos atores humanos. $\mathrm{O}$ que ocorre é que as capacidades de estruturação, mudança e restrição das instituições sociais fazem emergir novas percepções e disposições entre os indivíduos. São novas preferências e intenções que emergem sobre novos hábitos de pensamento e comportamento. Isso acaba fortalecendo e tornando uma instituição perene (HODGSON, 1994, 2001).

Finalmente Hodgson (2000) conclui reconhecendo que a atividade humana só pode ser compreendida como emergindo em um contexto de algumas instituições pré-existentes. Sugerese que a emergência e a estabilidade de algumas instituições podem ser reforçadas por processos em que restrições e canais institucionais levam a formação de hábitos de pensamento e comportamento concordantes. Esses argumentos indicam uma abordagem mais ampla da evolução de instituições, diminuindo a importância de comparações estáticas em favor de análises baseadas em processos.

\subsection{PROPOSTA DE ANÁLISE COMPLEMENTAR ENTRE AS TEORIAS EVOLUCIONÁRIA E INSTITUCIONALISTA}

Ao considerar o contexto histórico, cultural, econômico e político na teorização das ciências, a formação de ações institucionais e inovativas surgem no sistema econômico a partir do paradigma tecno-econômico. Embora não dediquem grandes esforços à interpretação das instituições, os Neo-Schumpeterianos a incorporam no emaranhado teórico e a consideram como um fator de influência nos movimentos de mudança estrutural.

A partir do desenvolvimento teórico elucidado por essas escolas, os conceitos de Paradigma Tecno-econômico de Freeman e Perez (1988) e Sistema Nacional de Inovação de Lundvall et al., (2002) surgiram e representam o amadurecimento dessa evolução. Dessa forma, firmados no compromisso de explicar as trajetórias de desenvolvimentos, as teorias tem o potencial de voltar seus elementos analíticos, de forma complementar, para a compreensão desses movimentos assimétricos que conformam o caminho das organizações.

Assim, agrupamento de todos os elementos que se associam de forma complementar, representados pelo Quadro 2, representam os principais pontos de conexão e que compõem o objetivo central desse trabalho.

O interesse, nesse estudo, especialmente, está na construção de uma proposta de integração complementar dos elementos social, político, tecnológico e institucional. A composição se inicia com a constatação de que os elementos que constituem as duas frentes teóricas derivam de uma ligação estreita com os elementos históricos que a conformaram. De um lado, os Neo-Schumpeterianos defendem que as trajetórias devem ser compreendidas a partir do seu contexto evolucionário em um sistema econômico (FREEMAN, 1995). Por outro, 
os institucionalistas afirmam que a história importa, pois tudo aquilo que se faz no presente deriva de uma atividade anterior (CONCEIÇÃO, 2000).

Observando, de forma integrada, o efeito desse elemento categórico, observa-se que a percepção história, convencionalmente chamada de Path Dependence, assume papel fundamental para a compreensão das trajetórias tecnológicas, pois é capaz de retomar os assuntos discutidos anteriormente e explicar a atual condição através dos alicerces que os mantém. Veblen (1898) já dizia que a consciência dos fatos depende da coincidência ou divergência de uma dada realidade vivenciada. Assim, a percepção de um avanço ou retrocesso dependerá, também, da percepção exercida anteriormente, reforçando, dessa forma, a importância da captação histórica dos acontecimentos a fim de avaliar os novos dados observados. Isso quer dizer que apenas conhecendo o percurso do ambiente será possível dimensionar o movimento exercido em determinado período, pois a percepção da mudança deriva da clareza existente entre o seu ponto e o dos seus vizinhos.

Nessa perspectiva, Conceição (2012) argumenta que as instituições são os elementos que não podem se dissociar dos processos dinâmicos de crescimento, desenvolvimento e de mudança tecnológica. Com isso, amparado na premissa de que a história se mostra como um elemento-chave para a compreensão dos cenários de desenvolvimento, de tal forma que as instituições perpetuam e estimulam a inovação tecnológica através do registro, disseminação e indução de mudanças.

Atrelada a essa consideração histórica, a perspectiva evolucionária também se faz presente no contexto complementar das duas teorias. Para os Neo-Schumpeterianos, o desafio se volta para a construção de uma teoria que reconheça o avanço tecnológico como um fator de impulsão do desenvolvimento econômico. No entanto, incorporar a influência do ambiente institucional nesse movimento, contribui com a regulação e ordenação do comportamento dos agentes, haja vista o poder intrínseco das instituições em diminuir as incertezas e conformar os comportamentos.

Além disso, o avanço tecnológico também representa uma ação internalizada, onde a busca e seleção de rotinas são exemplos de geradores de assimetrias nas empresas. Com isso, a existência de uma alternativa de ação gera a dependência salutar de uma decisão, que pode ou não trazer benefícios para a organização. Esses movimentos de escolha, por sua vez, estabelecem uma dinâmica própria a cada organização, gerando rotinas que podem induzir a mudança no processo inovativo (DOSI, 2006).

Ao aproximar a percepção Neo-Schumpeteriana da Institucionalista, Nelson e Winter (2005) propõe uma conceituação, dessa vez conectando a perspectiva evolucionária, própria do primeiro grupo, com as instituições. Para isso, o autor considera as instituições como sendo o resultado de um processo evolucionário, produtos e adaptações ao longo do tempo, ganhando diferentes características em momentos e contextos distintos.

Nessa concepção, Nelson e Winter (2005) assumem que esse movimento das condições não pode ser visto como um elemento finalizado, ou seja, com a mudança natural das instituições, novas realidades são criadas e recriadas em um processo contínuo e interpretativo do mercado. É justamente por isso que a teoria evolucionária se configura como um conjunto de fatos simbólicos que interpretam o presente e passado para elucidar proposições no futuro. No entanto, é preciso considerar que a situação que hoje se configura, irá modelar as instituições de amanhã. Veblen (1899) acreditava que isso acontecia através de um processo seletivo e coercitivo, desempenhado pela ação do homem sobre todas as coisas.

O caráter evolutivo, nesse sentido, ocorre ao passo em que os indivíduos criam processos para resolver problemas do dia-a-dia e, com eles, os hábitos surgem para fazer parte constituinte do espírito humano, não podendo ser dissociado das suas condições ambientais (HODGSON, 2006). O que se observa, com as constantes mudanças no ambiente, é que ocorre uma disseminação de hábitos, costumes, crenças, entre outras instituições que acabam, por 
assim dizer, reafirmando uma tendência de comportamentos perante a sociedade, por onde, obviamente, caminha a trajetória tecnológica.

Dessa forma, essa complementaridade ocorre quando se observa esse processo como um resultado de ações que deram origem ou originaram uma mudança institucional e tecnológica que, por vezes, emerge um avanço de trajetória. O pressuposto é que, mediante um caráter evolucionário, tanto as tecnologias, quanto as instituições saem da zona estacionária e passam a assumir novas proporções e significados na sociedade. Ambas as vertentes caminham, simultaneamente, para a resolução de algum problema ou superação de algum obstáculo.

Entende-se dessa forma, que a trajetória tecnológica passa por crivos de mudanças tais como custos de transação, avanços tecnológicos, movimentos institucionais, etc. que irão conduzir e discriminar, respectivamente, o caminho e a velocidade que a trajetória irá enfrentar. Por isso uma visão integrada dessas duas roupagens teóricas/analíticas faz sentido quando postas lado a lado para a explicação das trajetórias das organizações.

Mesmo que as instituições estejam trabalhando e desenvolvendo outros quesitos do mercado de trabalho, não é possível dissociar a sua atuação do sistema monetário, ou seja, todas elas, em maior ou menor grau, deverão se atentar para os efeitos dos custos produtivos e transacionais da organização. Isso porque, em grande monta, os resultados projetados irão depender, sumariamente, dos resultados financeiros adquiridos, os quais irão sustentar as atividades econômicas pelos próximos ciclos de desenvolvimento. Obviamente, a integração teórica não pretende voltar à unidade de análise para a pura transação, onde a eficiência transacional pode explicar toda e qualquer transação, mas a orientação deliberada, primariamente, pela Nova Economia Institucional pode contribuir com a explicação de movimentos existentes nas trajetórias tecnológicas.

Williamson (1985) propõe que a intenção de minimizar esses custos de transação pode variar de acordo com os atributos dessas transações que são: especificidade dos ativos envolvidos, frequência e duração das transações, além da racionalidade limitada e oportunismo. Dessa forma, tem-se que a forma organizacional mais eficiente para se trabalhar deriva de uma escolha (SAES, 2009). Essa escolha será realizada ao considerar os sistemas produtivos envolvidos em uma relação dialética com o ambiente institucional, pois à medida que ele se modifica, uma nova estrutura produtiva poderá ser lapidada.

De forma similar à denominação da NEI, o movimento institucional tende a trabalhar atendendo os interesses daqueles indivíduos que participam do tramite produtivo. No entanto, cabe salientar que, nos sistemas produtivos, entra em cena uma gama diversificada de variáveis que delimitam o comportamento e destino das transações. No contexto institucional, em geral, isso pode ser encarado sobre vários prismas como regras do jogo (FARINA, 2000), relações de poder (ZYLBERSTAJN, 1995), relações humanamente construídas que visam a eficiência (NORTH, 1991), movimento natural das transações (CONCEIÇÃO, 2000), hábitos conformados (HODGSON, 1994), entre outros ângulos de análise.

Observa-se que o instinto de autopreservação e a preocupação com a degradação do meio, conduzem o conjunto de instituições a criarem novos órgãos e tecnologias para amenizar os impactos negativos de várias atividades (PESSALI; DALTO, 2010). Assim, é possível observar que mesmo não tendo a intenção deliberada de trabalhar sob uma orientação otimizadora, esses cenários institucionais estão sendo influenciados por ideias acerca do desenvolvimento, afinal, a construção das complexas relações institucionais servem para dar movimento a esse processo. 
Quadro 1: Pressupostos analíticos com incidência complementar.

\begin{tabular}{|c|c|c|c|}
\hline Dimensão analítica & Neo-Schumpeterianos & Institucionalistas & Visão Complementar \\
\hline História & $\begin{array}{l}\text { - Contexto evolucionário; } \\
\text { - Caminho tomado pela trajetória } \\
\text { tecnológica. }\end{array}$ & $\begin{array}{l}\text { - Elemento difusor da tecnologia; } \\
\text { - Padrão para estabelecer } \\
\text { comparações; } \\
\text { - A história importa. }\end{array}$ & $\begin{array}{l}\text { - As instituições perpetuam e } \\
\text { estimulam a inovação tecnológica } \\
\text { pelo registro, disseminação e } \\
\text { indução de mudanças; } \\
\text {-Path Dependence; } \\
\text { - Meio que conduz a mudança pelos } \\
\text { anos. }\end{array}$ \\
\hline $\begin{array}{l}\text { Perspectiva } \\
\text { Evolucionária }\end{array}$ & $\begin{array}{l}\text { - Avanço tecnológico; } \\
\text { - Regularidade de comportamentos; }\end{array}$ & $\begin{array}{l}\text { - Regulação do comportamento; } \\
\text { - Estrutura de produção; } \\
\text { - Ações socialmente construídas. }\end{array}$ & $\begin{array}{l}\text { - Avanço tecnológico acompanha ou } \\
\text { define os padrões institucionais que } \\
\text { orientam a dinâmica inovativa. }\end{array}$ \\
\hline Custos & $\begin{array}{l}\text { - Influência da inovação nos custos } \\
\text { de produção; } \\
\text { - Competência; } \\
\text { - Regime tecnológico; } \\
\text { - Padrão setorial. }\end{array}$ & $\begin{array}{l}\text { - Ineficiência nas instituições } \\
\text { geram custos de transação e } \\
\text { produção; } \\
\text { - Atributos da transação; } \\
\text { - Rotina. }\end{array}$ & $\begin{array}{l}\text { - Ineficiências na estrutura } \\
\text { institucional, acompanhada da } \\
\text { influência na dinâmica inovativa } \\
\text { ocasionam custos de produção e } \\
\text { transação que derivam em perdas de } \\
\text { renda. }\end{array}$ \\
\hline Aprendizado & $\begin{array}{l}\text { - Conhecimento; } \\
\text { - Tecnologia; } \\
\text { - Rotina; } \\
\text { - Acúmulo de conhecimento. }\end{array}$ & $\begin{array}{l}\text { - Regularidade de comportamento; } \\
\text { - Respostas a problemas; } \\
\text { - Hábitos que geram rotinas; }\end{array}$ & $\begin{array}{l}\text { - As instituições propiciam os } \\
\text { acréscimos de conhecimentos que } \\
\text { são incorporados a cada nova onda } \\
\text { de desenvolvimento que se inserem } \\
\text { nas rotinas e aprimoramentos } \\
\text { tecnológicos. }\end{array}$ \\
\hline Mudança & $\begin{array}{l}\text { - Inovação; } \\
\text { - Estratégia; } \\
\text { - Janela de oportunidade. }\end{array}$ & $\begin{array}{l}\text { - Instituições Formais; } \\
\text { - Instituições Informais; } \\
\text { - Movimento natural, onde } \\
\text { múltiplos fatores induzem a } \\
\text { mudança. }\end{array}$ & $\begin{array}{l}\text { - Cabe ao ambiente institucional a } \\
\text { função de ritmar (lento ou rápido) o } \\
\text { processo de mudança que acontece } \\
\text { no âmbito tecnológico } \\
\text { competitivo; } \\
\text { - Processos interdependentes de } \\
\text { mudança tecnológica } \\
\text { institucional; } \\
\text { - Ação coletiva para a construção do } \\
\text { cenário socioeconômico. }\end{array}$ \\
\hline $\begin{array}{l}\text { Hábitos de } \\
\text { pensamento }\end{array}$ & $\begin{array}{l}\text { - Busca; } \\
\text { - Seleção; } \\
\text { - Rotina. }\end{array}$ & $\begin{array}{l}\text { - Hábitos de pensamento; } \\
\text { - Valores; } \\
\text { - Crenças; } \\
\text { - Cultura. }\end{array}$ & $\begin{array}{l}\text { - Ações institucionais se combinam } \\
\text { com as rotinas para promover o } \\
\text { progresso técnico e institucional se } \\
\text { adequando ou alterando os hábitos } \\
\text { existentes. }\end{array}$ \\
\hline Incentivos & $\begin{array}{l}\text { - Padrão setorial de inovação; } \\
\text { - Estrutura Industrial; } \\
\text { - Regime tecnológico. }\end{array}$ & $\begin{array}{l}\text { - Políticas agrícolas; } \\
\text { - Plano governamental; } \\
\text { - Perspectiva de crescimento } \\
\text { almejada pelos participantes; }\end{array}$ & $\begin{array}{l}\text {-Ações políticas que, ao serem } \\
\text { analisadas em conjunto, delimitam } \\
\text { um complexo campo de inter- } \\
\text { relacionamentos que culminam nas } \\
\text { projeções individuais. }\end{array}$ \\
\hline
\end{tabular}

Fonte: Elaboração própria.

O interesse que se estabelece na pauta administrativa dessa análise está na complementaridade de uma concepção que contemple a necessidade aparente de se relacionar no mercado financeiro e, ao mesmo tempo, a necessidade em constituir um movimento institucional que fortaleça e desenvolva as trajetórias tecnológicas. $\mathrm{O}$ destaque, portanto, se volta para o pressuposto de que os custos de transação devem ser encarados como balizadores do tramite produtivo, recebendo apoio direto do movimento institucional que se fortalece no bojo dos contextos produtivos. No limite, as ineficiências na estrutura institucional, atrelada à influência das inovações, podem ocasionar custos de produção e transação que derivam em perdas de renda, dificultando os investimentos futuros.

Outro item relevante para a análise complementar é o aprendizado que está presente, tanto no aparato tecnológico, quanto no institucional. A imersão das duas ementas ocorre no âmbito do conhecimento gerado em cada etapa de desenvolvimento que pode, por sua vez, gerar aprendizado para as instituições presentes. Assim, parte-se do pressuposto de que os aprendizados tecnológico e institucional interferem na trajetória tecnológica das empresas. Para isso, considera-se que a inovação tecnológica se origina nas esferas da própria sociedade, não sendo possível dissociar a criação desses processos inovativos da sua utilização na atividade produtiva, a fim de obter novos recursos para um novo ciclo de melhoramentos. Esses ciclos 
virtuosos podem ser vistos através do conhecimento aplicado, modificando, por exemplo, o design do produto, as atividades produtivas, entre outras mudanças.

Para Lundvall (2004) quando essas e outras adaptações se solidificam no corpo institucional, uma nova onda de busca e seleção de rotinas se iniciam, modificando o contexto novamente. Nesse sentido, a ruptura com o modelo anterior acontece ao passo que o aprendizado sustente as mudanças no ambiente institucional. Pressupõe, nesse caso, que as próprias transações geram aprendizado para as organizações e, quando são analisadas de forma complementar, observa-se que a inovação está intimamente relacionada com a constante preocupação em melhorar/aperfeiçoar em algum aspecto os produtos e serviços imersos em um determinado paradigma tecnológico. Hodgson (2001) sugere que a emergência e a estabilidade de algumas instituições podem ser reforçadas por processos em que restrições e canais institucionais levam a formação de hábitos de pensamento e comportamento concordantes. A interação entre os elementos que conformam o paradigma tecnológico contribuem para a criação e perpetuação das instituições no setor.

Para Pérez (1992), o conhecimento constitui um fator de produção, pois envolve outros elos da cadeia produtiva, tais como o trabalho, o capital e o uso de recursos disponíveis. Em conjunto, Lundvall (2004) ressalta que ao se considerar o caráter dinâmico dos paradigmas, é preciso pressupor que o conhecimento é uma combinação de habilidades individuais e coletivas que se movem para atualizar o ambiente institucional. Para tanto, a geração do conhecimento ocorre mediante as reformas institucionais e tecnológicas simultâneas ao movimento social e econômico. Assim, o pressuposto é de que as instituições propiciam os acréscimos de conhecimentos que são incorporados a cada nova onda de desenvolvimento que se inserem nas rotinas e aprimoramentos tecnológicos.

O aprendizado, nesses termos, é encarado como uma espécie de rotina e podem ocorrer, de acordo com Malerba (1992), com learning by doing, learning by using, learning by interacting, learning from advances in science and technology, learning from inter-industry, e learning by searching. Todas essas formas de aprendizado constituem uma rotina destinada a preparar as empresas para o futuro. Com isso, o aprendizado deriva do acúmulo de conhecimento, do qual as rotinas preparam as pessoas/organizações para aprender constantemente, ou seja, forma-se um círculo virtuoso em que os próprios agentes legitimam essa necessidade.

Com o auxílio de um pensamento voltado para o desenvolvimento, alguns pensadores com tendências evolucionárias e Neo-Institucionalistas difundem preceitos em comum a respeito da utilização do conhecimento no contexto produtivo, enfatizando a importância da informação, cumulatividade de conhecimento, novas interpretações para as múltiplas formas de aprendizado e presença constante das inovações tecnológicas na vanguarda do desenvolvimento econômico. Para Lemos (1999), a intersecção entre conhecimento e inovação individualiza o desenvolvimento de capacidades, tanto tecnológicas, quanto científicas e institucionais.

Em continuidade, as mudanças demonstram ser outro fator de impacto quando as duas teorias são confrontadas. Isso porque uma série de novos elementos são conformados nessa junção, tais como as inovações, as instituições formais, informais, entre outros. Essa mudança, do ponto de vista Neo-Schumpeteriano, deve ser vista como o delimitador da inovação, pois é a partir dessas mudanças que o setor sente os impactos do desenvolvimento tecnológico. Do ponto de vista institucional, essas mudanças recebem um tom evolucionista, mas não se traduzem no simples movimento da eficiência produtiva, ou seja, é preciso pensar em um movimento puro, podendo avançar ou retroceder em algum aspecto.

Nesse sentido, a inovação não é fruto apenas de um cálculo de otimização, mas sim do recurso a uma heurística, expressa, de forma legitimada, por regras e procedimentos. Esse processo de busca é fundamentado em conhecimentos humanos, dos quais se acumulam pelas formas de aprendizado, contribuindo para gerar inovações. 
North (1991) procurou observar as instituições como as restrições humanamente construídas nas quais interagem as estruturas política, econômica e social. As regras formais são compostas por leis, constituição e direitos de propriedade, por outro lado, as sanções, tradições e códigos de conduta são classificados como restrições informais. Com isso, se a inovação pode ser vista como uma mudança na tecnologia social, também é possível assumir essa perspectiva macro desenvolvimentista na tentativa de observar a construção da trajetória tecnológica sob essa influência formal e informal que são capazes de condicionar o ambiente tecnológico e social.

Contudo, a complementaridade teórica poderá perfazer a interação bilateral dos fatos. Tatsch (2006) reforça a ideia de interação teórica, dizendo que os processos de inovação e difusão institucional não são independentes, pois fazem parte de um mesmo processo do qual as empresas se envolvem em múltiplos processos de mudanças que, ao longo do tempo, são percebidas e trabalhadas de acordo com a sua aprendizagem. Dessa forma, o pressuposto que se instaura na análise é de que cabe ao ambiente institucional a função de ritmar (lento ou rápido) o processo de mudança que acontece no âmbito tecnológico e competitivo.

A aproximação que diz respeito aos hábitos de vida e consequentemente das empresas surgem nessa abordagem integrada. $O$ interesse respaldado nos hábitos se justifica pelo eminente resultado que esse elemento gera quando está instaurado nas organizações. Pela vertente Neo-Schumpeteriana, esses hábitos se revelam através dos processos de busca, seleção e utilização de uma rotina ótima. No caso dos institucionalistas, os hábitos aparecem pelas crenças, costumes, hábitos de vida e cultura.

Ao detalhar essa aproximação, observa-se que ao assumir o compromisso de buscar por novas oportunidades e observar a realidade socioeconômica, as empresas projetam as suas atividades para o futuro, pressionando os processamentos a favor desse novo cenário idealizado.

As mudanças, que irão derivar desse posicionamento, tem início na busca incessante por inovações de processos e produtos, que por sua vez, são submetidas aos mecanismos de seleção inerentes à concorrência de mercado (POSSAS, 1990). A procura estabelecida deve ser explicada para além da eficiência estática, ou seja, considera-se aqui uma eficiência dinâmica, onde o potencial inovativo das organizações é delineado a partir das habilidades, competências, experiências, dentre outros elementos que propulsionam a mudança.

Nessa concepção, Nelson e Winter (2005) defendem que ao estabelecer um padrão de comportamento, as empresas entram em uma trajetória tecnológica, recebendo um impulso próprio e multifatorial em suas atividades. Geralmente, no escopo analítico dos NeoSchumpeterianos, essas mudanças são impulsionadas pelo progresso técnico. Arend (2009) reforça essa ideia e salienta que a trajetória tecnológica contribui no balizamento dessas atividades, fornecendo um caminho onde existem oportunidades e mecanismos para romper com a fronteira tecnológica - mais alto nível alcançado em relação a uma trajetória tecnológica - e iniciar novos processos de busca e seleção.

A trajetória contribui com a mobilização dos recursos disponíveis para buscar um novo caminho. Autores como Nelson e Winter (2005) e Dosi (2006) são tomados como referência para a interpretação dessas situações, como é o caso das rotinas geradas e aprimoradas pelas organizações. De forma concomitante, outros autores como Hodgson (2001) e Conceição (2000) apostam na presença dos hábitos, costumes e crenças para a delimitação institucional da mudança. Para eles, o movimento ocasionado irá depender do real interesse dos participantes, não sendo possível responder por eles como um simples movimento de eficiência.

Com isso, propõe-se que a visão complementar irá contribuir com a análise simultânea daqueles elementos que impulsionaram e incentivaram a mudança tecnológica e institucional. Para que o progresso técnico exista no campo, parte-se do pressuposto de que uma série de outras instituições necessite existir para emergir uma determinada empresa em uma trajetória 
tecnológica. Assim, as ações institucionais se combinam com as rotinas para promover o progresso técnico e institucional, adequando ou alterando os hábitos existentes.

Finalmente, a aproximação que correlaciona os incentivos do mercado com os regimes tecnológicos e setoriais delimitam uma nova categoria, aqui denominada de Incentivos. De um lado, a análise do regime tecnológico contribuirá com a determinação dos incentivos e dificuldades que as unidades produtivas enfrentaram ao longo do tempo e, principalmente, mediante um dado ambiente tecnológico. De outro lado, mas não distante, estão os incentivos governamentais e institucionais que acabam por estimular a produção e movimentação dos agentes no mercado.

Dessa forma, esse movimento está relacionado à trajetória organizacional e tecnológica das organizações, pois mesmo com um mercado repleto de oportunidades, cabe à organização identificar e aproveitar os recursos e se posicionar na competição. Nessa perspectiva, Nelson e Winter (2006) relatam que os regimes tecnológicos devem ser interpretados como a fronteira das aptidões realizáveis, com base nas limitações econômicas, físicas, biológicas entre outras, dentro de uma maneira genericamente definida de fazer as coisas. Com isso, cada setor apresenta uma velocidade distinta de inovação, fazendo com que seja necessário, do ponto de vista de Orsenigo (1995), haver uma interpretação dessas condições, a fim de avaliar os incentivos por parte das organizações e desenvolver estratégias e investimentos que atendam às pressões do setor. O importante é manter ativa a percepção de que o regime tecnológico interfere no comportamento inovativo das empresas.

No entanto, mesmo com percepções e ações diferenciadas, é possível identificar um comportamento homogêneo em relação ao processo inovativo, respondendo diretamente a um padrão setorial. Pavitt (1984) sinaliza que as empresas dos setores intensivos em tecnologia são inovadoras e dispõem, por exemplo, de centros de pesquisa e desenvolvimento, perfazendo uma combinação entre patentes, segredos, defasagens técnicas naturais e habilidades específicas.

De forma simultânea, esses comportamentos devem ser interpretados mediante as ações institucionais que circunscrevem essas empresas. Isso quer dizer que não se deve dissociar os padrões de investimento e desenvolvimento de um setor, dos incentivos governamentais, das políticas agrícolas, etc. Em cada momento da história é possível identificar, mediante documentos, os planos de desenvolvimento e incentivos que balizaram os investimentos do setor. Assim, as ações políticas que, ao serem analisadas em conjunto, delimitam um complexo campo de inter-relacionamentos que culminam nas projeções individuais.

\section{CONSIDERAÇÕES FINAIS}

A literatura Neo-Schumpeteriana defende que os processos inovativos contribuem com a difusão de novas tecnologias e não podem ser entendidos de forma independente, pois fazem parte de mesmo processo de desenvolvimento. Atrelada a essa literatura, a abordagem institucional defende que os processos institucionais impulsionam o movimento dos agentes, que podem ou não caminhar e desenvolver novas tecnologias. $O$ fato é que as duas vertentes trabalham com o pressuposto de mudanças contínuas no campo, introduzindo novas formas de se fazer e pensar o seguimento.

Commons (1931) também propõe uma visão diferenciada para as instituições, indicando que elas devem ser compreendidas como uma ação coletiva de controle, liberdade expansão das ações. Nessa perspectiva a ação coletiva, além de envolver todas as formas de controle social (família, associações, sindicato, o Estado, etc.), também trabalha com o princípio comum de que todas as organizações sofrem com a presença de maior ou menor grau de influência.

Nessa perspectiva, entende-se que a interação das instituições e as mudanças tecnológicas promovem posicionamentos teóricos congruentes. Essa compatibilidade se inicia com a própria noção de instituição, talvez em função das raízes históricas e estruturais que lhe 
são específicas, que garante trajetórias de crescimento anacrônicas no ambiente socioeconômico. Além disso, o caráter cumulativo do aprendizado também está presente nessa avaliação, pois a história também importa, afinal, as trajetórias de crescimento são criadas ao longo do tempo, sendo condizente com a velocidade e condicionamentos do seu seguimento. Para ele, as instituições importam para analisar o crescimento, porque determinam as trajetórias nos múltiplos ambientes. Trata-se, portanto de um misto entre escolhas individuais, contratos, organizações e instituições, ou seja, todas atuando no mesmo espaço e ao mesmo tempo.

Assim, o objetivo inicial do trabalho [construção de um quadro analítico que aproxime as duas teorias - Neo-Schumpeteriana e Institucionalista - com o propósito de angariar elementos que tenham o mesmo aporte epistemológico e, ainda, contribuam com o desenvolvimento futuro de novas interpretações no campo] foi cumprido. O Quadro 1 apresentou os principais pressupostos analíticos oriundos da aproximação teórica complementar das referidas abordagens. Isso faz surgir uma nova possibilidade de análise, dessa vez considerando para além das linhas estreitas de cada teoria.

A próspera utilização do modelo poderá contribuir com a avaliação de cenários complexos das cadeias produtivas onde interagem, simultaneamente, entes da esfera civil, política, governamental, entre outras classes de interesse. Obviamente, existem limitações para a utilização dos pressupostos analíticos e deve, em cada caso, ser estudado para ter conhecimento das reais aproximações que serão conquistadas. A sugestão é que, em estudos futuros, o modelo analítico seja utilizado para a construção de categorias analíticas capazes de observar as cadeias produtivas do Brasil.

\section{REFERÊNCIAS BIBLIOGRÁFICAS}

AREND, M. 50 anos de industrialização do Brasil (1955-2005): uma análise evolucionaria. (Tese de doutorado). PPGE/UFRGS, Porto Alegre, 2009.

COMMONS, J. R. Institutional economics. American Economic Review, v. 21, p. 648-657, 1931

CONCEIÇÃO, Octavio A. C. Instituições, crescimento e mudança na ótica institucionalista. Tese (Doutoramento em Economia) - Programa de Pós-Graduação em Economia, Universidade Federal do Rio Grande do Sul, Porto Alegre. Porto Alegre, 2000.

A dimensão institucional do processo de crescimento econômico: inovações e mudanças institucionais, rotinas e tecnologia social. Economia e Sociedade, Campinas, v. 17, n. 1 (32), p. 85-105, abr. 2008.

. Há compatibilidade entre a tecnologia social de Nelson e a causalidade vebleniana de

Hodgson?. Revista de Economia Política, v32, n. 1, janeiro-março, p. 109-127, 2012.

DEWEY, John. Human nature and conduct: an introduction to social psychology. New York: Random House, 1950.

DOSI, G. The nature of the innovative process. In: DOSI, G. et all (org). Technical change and economic theory. London: MERIT, 1988, p.221-238.

. Mudança técnica e Transformação Industrial. Campinas: Ed. Unicamp, 2006.

FARINA, Elizabeth M.M.Q. Organização Industrial no Agribusiness. In: ZYLBERSZTAJN, Décio; NEVES, Marcos F. (Orgs.). Economia e Gestão de Negócios Agroalimentares: indústria de alimentos, indústria de insumos, produção agropecuária, distribuição. 1.ed. São Paulo: Pioneira, 2000.

FARINA, E. M. M. Q.; AZEVEDO, P. F.; SAES, M. S. M. Competitividade: mercado, estado e organizações. São Paulo: Editora Singular, 1997.

FREEMAN, C. The national System of innovation in historical perspective. Cambridge Journal of Economics, v.19, n.1, p. 5-24, 1995. 
FREEMAN, C.; PEREZ, C. Structural crisis of adjustment: business cycles and investment behaviour. In: DOSI, G.; FREEMAN, C.; NELSON, R.; SILVERBERG, G.; SOETE, L. (eds). Technical change and economic theory. London: Pinter, p. 38-66, 1988.

HODGSON, Geoffrey. The Return of Institutional Economics. In: SMELSER, Neil; SWEDBERG, Richard. (eds.) The Handbook of Economic Sociology. New York: Princeton University Press, 1994.

. What is the essence of institutional economics? In: Annual meeting of the association for evolutionary economics. Boston, Massachusetts, 6-9 jan., 2000.

. A evolução das instituições: uma agenda para pesquisa teórica futura. Revista

Econômica, v.3, n.1, p.97-125, junho, 2001.

What are Institutions? Journal of Economic Issues, vol.40, n.1, mar., 2006.

KLEIN, Benjamin. CRAWFORD, Robert G. ALCHIAN, Armen A. Vertical Integration, Appropriable Rents, and the Competitive Contracting Process. Journal of Law and Economics, v. 21, n. 2, p. 297-326, 1978.

LAPLANE,M.; SARTI, F. Investimento direto estrangeiro e a retomada do crescimento sustentado nos anos 90. Economia e Sociedade, Campinas, n. 8, p. 143-181, jun. 1997.

LEMOS, C. Inovação da era do conhecimento. In: LASTRES, H. M. M.; ALBAGI, S. Informação e globalização na era do conhecimento. Rio de Janeiro, 1999.

LUNDVALL, B.A; JOHNSON, B.; ANDERSEN, E.S.; DALUM, B. National systems of production, innovation and competence building. Research Policy, n.31, p. 213-231, 2002.

Introduction to 'technological infrastructure and international competitiveness' by

Christopher Freeman', Industrial and Corporate Change, v. 13, n. 3, p. 531-539, 2004.

MALERBA, F. Learning by firms and incremental technical change. The Economic Journal, 1992.

MINAYO, M.C.S. Pesquisa Social: teoria, método e criatividade. 29 ed. Petrópolis, RJ: Vozes, 2010.

MITCHELL, W. C. Os ciclos econômicos e suas causas. São Paulo: Abril Cultural, 1984.

MONASTERIO, L. M. Guia para Veblen: um estudo acerca da economia evolucionária. Pelotas: EDUFPEL, 1998.

NELSON, R; WINTER, S. Uma teoria evolucionaria da mudança econômica. Unicamp, 2006.

NONAKA, I.; TAKEUCHI, H. Criação de conhecimento na empresa. São Paulo: Campus, 1997.

NORTH, Douglass C. Institutions. The Journal of Economic Perspectives, v.5, n. 1, p. 97 $112,1991$.

Instituciones, cambio institucional y desempeño económico. Ciudad de México :

Fondo de Cultura Económica, 1993.

ORSENIGO, Luigi. Tecnological regimes, patterns of innovative activities and industrial dynamics - A survey of empirical evidence and of some theoretical models. Cahiers d'economie et sociologie rurales, n. 37, p. 26-67, 1995.

PAVITT, K. Sectors patterns of technical change: Toward a taxonomy and theory. Research Policy, 1984.

PEREZ, C. Cambio Técnico, Restructuration Competitiva y Reforma Institucional en los Países en Desarollo. El Trimestre Económico, v.61, 1992.

PESSALI, Huáscar F.; DALTO, Fabiano. A mesoeconomia do desenvolvimento econômico: o papel das instituições. Nova Economia, v.20, n 1, p. 11-37, 2010.

POSSAS, M.L. A economia política no Brasil hoje. Revista de Economia Política, São Paulo, SP, v. 10, n.2, p. 95-115, 1990.

SIMON, H. Models of Man: social and rational. New York: Wiley, 1957. 
TAVARES, P.V.; KRETZER, J.; MEDEIROS, N. Economia Neo-Schumpeteriana: expoentes evolucionários e desafios endógenos da indústria brasileira. Economia Ensaios, v 19, n. 3, Dezembro, 2005.

TIGRE, P. B. Gestão da inovação: A economia da tecnologia no Brasil. São Paulo: Campus, 2006.

VEBLEN, T. B. A. A teoria da classe ociosa: um estudo econômico das instituições. São Paulo: Pioneira, 1965. (1a. ed. 1899).

. Engineers and the price system. New York: Viking Press, reimp. 1959. (1a. ed. 1921) . Why is economics not an evolutionary science?. Quarterly Journal of Economics,

vol. 12, no. 3, July, 373-97, 1898.

Essays, reviews and reports: previously uncollected writings. DORFMAN, J (ed.).

Inclui a introdução New Light on Veblen de Joseph Dorfman. Clifton, NJ: Augustus M. Kelley, 1973.

WILLIAMSON, O.E. Markets and Hierarchies. New York Free Press, 1975.

The economic institutions of capitalism: firms, markets, relational contracting. New York: New York Press, 1985.

. The new institutional economics: taking stock, looking ahead. Journal of Economic Literature. v. 38, p. 595-613, 2000.

ZYLBERSZTAJN, Decio. A estrutura de governança e coordenação do agribusiness: uma aplicação da nova economia das instituições. 1995. 238 f. Tese (Livre-Docência) - Faculdade de Economia, Administração e Contabilidade, Universidade de São Paulo, São Paulo, 1995.

ZYSMAN, John. How institutions create historically rooted trajectories of growth. Industrial and Corporate Change, v. 3, n. 1, p. 243-283, 1994. 